\title{
MICROSCOPIC STUDY OF THE COAL TAR CARBONACEOUS DISPERSED PHASE
}

\author{
Ukrainian State Research Institute of Carbochemistry UKHIN \\ 7, Vesnina str., 61023 Kharkov, Ukraine; nto@ukhin.org.ua
}

Received: February 28, 2011 / Revised: M arch 17, 2011 / Accepted: M ay 30, 2011

() Cheshko F., 2011

\begin{abstract}
The results are given for studying the coal tar carbonaceous dispersed phase with a number of microscopes of various principles of operation. High trend is shown for the dispersed particles to form stabile aggregates and to adsorb other tar compounds on their surface. The conclusion is made that the selective extraction of the dispersed phase from the coal tar is fundamentally impossible. The well-founded hypothesis is expressed about the technological practicability of the tar dispersed phase aggregates destruction for the quality upgrading of the tar-based products.
\end{abstract}

Keywords: coal tar, dispersed phase, dispersive medium, quinoline insolubles, particles, microscopy, aggregation, surface.

\section{Introduction}

It is known $[1,2]$, that the coal tar (CT) shows all the characteristic features of the dispersed systems. The dispersed phase of the tar is dissipated in the form of solid, liquid and gaseous fine-dispersed particles inside the dispersive medium which is the multicomponent mixture of organic compounds and their permolecular lumps.

The chemical composition of coal tars and pitches obtained from them (the $\mathrm{CT}$ rectification indistillable residue) is quite complicated; the most part of its components cannot be identified through chemical analysis. This is especially true in respect to the most macromolecular components of tars and pitches. Therefore it is common practice in coke chemistry and adjoining fields to characterize tars and pitches by the so-called group composition which describes the components` capability to dissolve in various organic solvents (isooctane or petroleum ether, toluene, quinoline or anthracene).

The most macromolecular part of CT and pitches is the group of toluene insolubles ( $\alpha$-fraction). It is subdivided into the $\alpha_{1}$-fraction (quinoline or anthracene insolubles) and $\alpha_{2}$-fraction (compounds soluble in quinoline but insoluble in toluene). $\alpha_{1}$-Fraction of coal pitches is also subdivided into two parts: primary and secondary quinoline insolubles. The primary $\alpha_{1}$-fraction includes dispersed components which are present in the tar initially and are transferred completely into pitch when they were produced. Those are ash particles of coal, semicoke, coke and oven brickwork carried away from the coking chamber by the coke gas flow (the so-called $\alpha_{1^{-}}$ carryover, its content correlates with ash content), and also products of the hydrocarbons vapor-phased pyrolysis inside the coking oven headspace. It is common practice to divide the CT according to its primary $\alpha_{1}$-fraction mass concentration into low-pyrolized $(\leq 3 \%)$, mediumpyrolized (3-6\%) and highly-pyrolized $(\geq 6 \%)$ ones [2].

The secondary constituent of the $\alpha_{1}$-fraction is formed during the processing of initial ("soft") pitch and consists of the most macromolecular products of the pitch hydrocarbons liquid-phase pyrolysis [3, 4]. Differences in the generating conditions of the quinoline insoluble constituents predetermine differences in their properties and effects upon the CT and pitch characteristics. Thus primary $\alpha_{1}$-fraction has the most condensed structure and does not show any binding properties $[2,5]$.

The quinoline insoluble constituents of coal tars and pitches are not inert fillers. They form properties of the material as a physico-chemical system to a great extend. The supposition was expressed repeatedly that $\alpha_{1}$-fraction particles are capable of adsorbing various CT and pitch components on their surface and of building the so-called complex structural units (CSU) [6], which are considered by a number of investigators as the base element of the pitches dispersed structure regardless of the pitches production technique and their basic material nature $[2,7$, 8]. Concerning the primary constituent of the quinoline insolubles this is partly confirmed by the fact that the residues after the industrial CT cleaning from $\alpha_{1}$-fraction contain significant (up to $50 \%$ ) amounts of other fractions of CT group composition regardless the technique used (settling or filtering centrifugation, filtration under vacuum or under pressure) $[9,10]$. 
It should be mentioned here that the interaction between a dispersed phase and a dispersion medium is determined by:

- total phase-medium contact surface, i.e. the dispersed particles specific surface which is in its turn the function of their texture;

- chemical and physical properties of the particles surface, particularly the capability for the dispersion medium components adsorption.

Particularly the second point determines, concerning CT, the very essence of the "dispersed phase" concept, the part of the dispersed phase being played by the particles themselves or by the CSU mentioned above.

As follows from the above, general factors that effect physico-chemical conditions of CT (and consequently the pitch as well) as dispersed systems, the mass content of quinoline insolubles and also their sizes and surface characteristics must be recognized. Besides it is obvious that such characteristics influence significantly the coal tar properties as well as those of the CT indistillable residue and the processes going with the treatment of both materials.

As for the size of the $\alpha_{1}$-fraction particles, there are a number of publications concerning investigations [1115]. But the given data are quite contradictory: a particle size interval ranges from 1-2 $\mu \mathrm{m}$ [11] to $0-125 \mu \mathrm{m}$ [13]. The $\alpha_{1}$-fraction extracted by some technique from the initial sample was the subject of studying in all the cases and this may account for rather wide range of results. Such extraction techniques are based upon the filtration of great volumes of tar or pitch (including under pressure varieties), centrifugation or extraction. The residues extracted appear as a compact packed paste (G. Romovacek [11] used the term "cake"). The residue obtained was then subjected to dispersing (sometimes with the use of ultrasonic or other destructive factor), repeated washing with solvents (such as toluene) and drying. This fact leads to errors in measuring the $\alpha_{1^{-}}$ fraction particle sizes. Under such a treatment of the analyte such bound particles may form conglomerates that are incapable of separation during the following washings (as shown in [11]), and on the other hand such particle aggregates present in the tars and transferred into the pitches may be destroyed that effect those materials characteristics in the same way as individual particles (for example concerning the blocking of impregnated material porosity and so on). One more factor capable of affecting the results is the uncompleted extraction of the coal and coke tailings (so called pitch sands) from the CT under study which is probably the cause of finding particles of $\alpha_{1}$-carryover with size up to $60 \mu \mathrm{m}$ and more in the quinoline insolubles.

According to the authors themselves the results obtained after such treatment cannot give any adequate notion of the real $\alpha_{1}$-fraction particle size [12]. In this respect the attempts of investigating the quinoline insolubles using such techniques that do not include particles extraction appear more informative - for example studying of the tar solutions in quinoline with the use of the scanning microscope $[16,17]$.

As for observing the particle surface, the process involves all the above mentioned difficulties. Besides, the studying is further complicated by the microscopes design peculiarities. Thus, for example with the equipment of transmitting light (transillumination of a solution layer), as in publications $[16,17]$, the $\alpha_{1}$-fraction particles appear as a dark contrast projections (shadows) on the light background and this fact excludes any possibility to assess their three-dimensional form and their surface structure so.

The optical microscopes that demonstrate subjects in a reflected light are oriented generally onto observation of the slices of the compressed paste of the extracted particles that does not permit to survey the natural outer surface of the particles. The studying of the threedimensional solid (bulked all the more) samples or liquids (in three dimensions) is possible only for such apparatus under the relatively low magnification and with the use of some special technique.

Quite contrary, the rather high magnification is characteristic for the electron microscopes; therefore they isolate quite a narrow field of survey and consequently range down the intervals of observable particles size. The use of such equipment is more practicable in the countries where high capacity centrifuges are in operation for cleaning the tar from water and coarse tailings and therefore the size of the primary $\alpha_{1}$-fraction particles is generally $1-3 \mu \mathrm{m}$ and less. In Ukraine such equipment is just starting to be introduced into practice. Up to now almost on every coke plant the CT is cleaned in the power-operated clarifiers for account of the gravitational sedimentation of the tailings under the temperature of $343-353 \mathrm{~K}$ thus providing a removal of only the coarsest part of the pitch sands.

When comparing the results of different studies it is also necessary to take into account that not only the tar settle technique but a whole number of other technology factors (raw material and technological regime of carbonization, the coking oven design, the presence or absence of hydro- or steam injection and so on) may effect the qunoline insolubles characteristics.

On the basis of above-stated, considering the complexity of dispersion medium composition and dispersed phase texture of CT it appears practical to carry on the studying aiming at the visual assessment of surface characteristics and interaction of the primary $\alpha_{1}$-fraction particles with the use of a number of different survey techniques. In other words the microscopes of various principles of operation are needed as well as various sample preparation techniques. In this case comparing and generalizing of the obtained pictures (including their 
producing technique) will provide a possibility to shape some notion of the quinoline insolubles characteristics and their behavior in the tar.

Such studies are the subject of this work.

\section{Experimental}

An industrial sample of the low-pyrolysed CT (JSC "AKHZ") was chosen as the initial material of the studying, the characteristics of which are shown in the Table. The choice of the low-pyrolized CT proceeded from the consideration that the tars with such a low rate of density can usually be cleared from the tailings completely enough under production conditions and consequently clogging of the dispersed phase with the pitch sands particles is minimal in this case.

Table

Initial tar characteristics

\begin{tabular}{|c|c|c|}
\hline \multicolumn{2}{|c|}{ Characteristic } & Value \\
\hline \multicolumn{2}{|c|}{ Density, $\mathrm{kg} / \mathrm{m}^{3}$ dry basis } & 1164 \\
\hline \multicolumn{2}{|c|}{ Water, $\%$ mass fraction } & 3.0 \\
\hline \multicolumn{2}{|c|}{$\alpha_{1}$-Fraction, $\%$ mass fraction } & 1.6 \\
\hline \multicolumn{2}{|c|}{$\alpha$-Fraction, $\%$ mass fraction } & 4.2 \\
\hline \multicolumn{2}{|l|}{ Ash, \% } & 0.07 \\
\hline \multirow{7}{*}{$\begin{array}{l}\text { Rectification } \\
\text { characteristics }\end{array}$} & Temperature, $\mathrm{K}$ & Boils out, $\%$ \\
\hline & $\leq 453$ & 2.7 \\
\hline & $453-473$ & 1.0 \\
\hline & $473-503$ & 15.4 \\
\hline & $503-573$ & 9.3 \\
\hline & $573-633$ & 11.9 \\
\hline & $\geq 633$ & 59.3 \\
\hline
\end{tabular}

In order to concentrate the primary quinoline insolubles (to facilitate their extraction for the studying) this tar was distilled in the laboratory distillation device according to the technique which was practiced for comparative analysis of different tars [18] under conditions which prevented formation of the secondary $\alpha_{1}$-fraction [19].

Also the solution of the tar in quinoline $1: 10$ was prepared (the dissolving procedure carried out at the temperature of 368-373 K).

For further microscopic studying the following samples were prepared:

1. Primary quinoline insolubles extracted from the solution by means of the solvent evaporation. To obtain this preparation a drop of tar quinoline solution (concentration 1:10) was placed between the slide and cover glasses and kept for a long time at a room temperature. The films contracted gradually as a result of the solvent evaporation and under effect of surface tension; along with that the color was shifting from evenly brown at the beginning to darker and darker shade at a gradient from the sample center to its periphery (see Fig. 1).

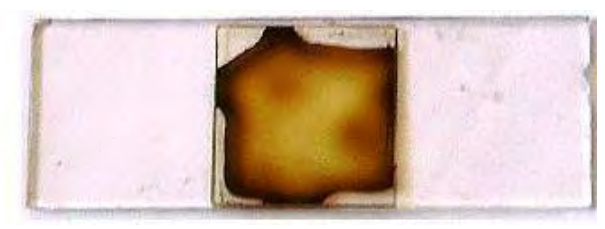

Fig. 1. Tar quinoline solution kept over a period of seven days between the slide and cover glasses

The growing of the dispersed particles concentration on the samples periphery and on the surface (side) film of the solution drop during its "shrinkage" under such conditions is due to the forces of Brownian motion of the solution molecules and also results from the volatile solvent vapors outflow. Along with the dispersed particles accumulation on the surface film the rate of the surface tension goes down. After certain threshold concentration had achieved the surface tension energy became lower than the Brownian motion energy and as a result of this the particles were shoved outside the bounds of the interface surface where they formed dark clusters visible by an unaided eye and dry transparent spaces containing but single particles of $\alpha_{1}$-fraction.

2. Dispersed particles extracted from the indistillable residue of CT by means of the analytical method of determining the $\alpha_{1}$-fraction mass fraction using the thermo-filtering technique. The technique includes: $373 \mathrm{~K}$;

- dissolving of the tar portion in quinoline at 368-

- filtration of the obtained solution at 368-373 K through the double filter «white string» using a special heated funnel;

- washing of the residue on the filter with $30 \mathrm{~cm}^{3}$ of hot quinoline and then with toluene heated to a boiling point.

The washing was carried out up to discoloring of the filtrate; the residue was dried till constant weight and stored in exsiccator.

The samples obtained were investigated by the microscopes of various designs.

\section{Results and Discussion}

The solution of the tar in quinoline was studied on the slide glass by the microscope "Neofot" (reflected light). This microscope is designed in such a way that the sample is placed over the objective with the mounted side facing down.

The observation of the solution revealed (see Fig. 2 ) the ability of the $\alpha_{1}$-fraction particles to aggregate. Two varieties of the aggregates were observed: 
1 - primary ones, densely packed (caked), probably existed in the tar before dissolving;

2 - secondary ones, formed in the solution, particles adjoin each other less closely or they are divided by the film of solution (at the same time Fig. 2 shows that the primary aggregate constituents a part of the secondary aggregate).

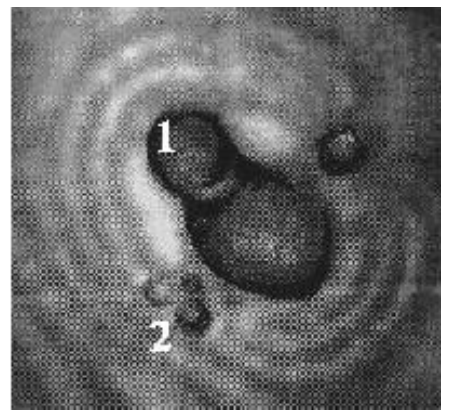

Fig. 2. Primary and secondary $\alpha_{1}$-fraction particles aggregates of the coal tar (magnification of 500x)

The concentric striated structures (CSS) which are shown in Fig. 2 demonstrated a behavior of the material entities (that is when being focused they were gradually gaining or losing sharpness and not appearing or disappearing instantly as the optical effects do). Probably they are constituents of the solution relief formed as a result of the scintillating motion of particles originated by surface tension. The other possible explanation of the CSS formation is selective adsorption capacity of the $\alpha_{1^{-}}$ fraction particles. In any case those structures appeared when observing the overturned sample only. Whatever the case, the attention must be paid to the fact that primary aggregates and single particles make CSS of a similar structure.

The layer of the CT quinoline solution (nearly $40 \mu \mathrm{m}$ thick) between slide and cover glasses was observed by the microscope at the lighting generated by the red laser beam orientated angularly to the plane of the sample (the design was engineered by V. M. Shmalko).

Such a way of lighting permits to reveal the finest particles (nanorange of dispersity) for account of the light diffraction effect. In this case not the particles themselves are observed but the bright spots of light over them. Concerning more coarse particles (micron size) the probability is of interest to observe the illuminating effects on the surface irregularities of any single object. Such use of the side lighting microscopes (for example for studying microfissures) is also known [20, 21]. The above-stated suggest that the complex lighting which combines the components of reflected and side ones also provides conditions for diffraction on the relief features of the particles and should permit to obtain more complete information about the dispersed phase compared with each of those kinds of lighting alone.
The results of observation are shown in Fig. 3. As shown in Fig. 4, the bright star-shaped spots which appeared to be particles at the beginning prove to be aggregates of finer particles with the increase of magnification. On both figures one and the same particle is marked by the pointing arrow. Two more aggregates may be observed in Fig. 4 - either composed of finer particles on the initial stage of formation or more remotely sited from the sample surface and consequently less distinct.

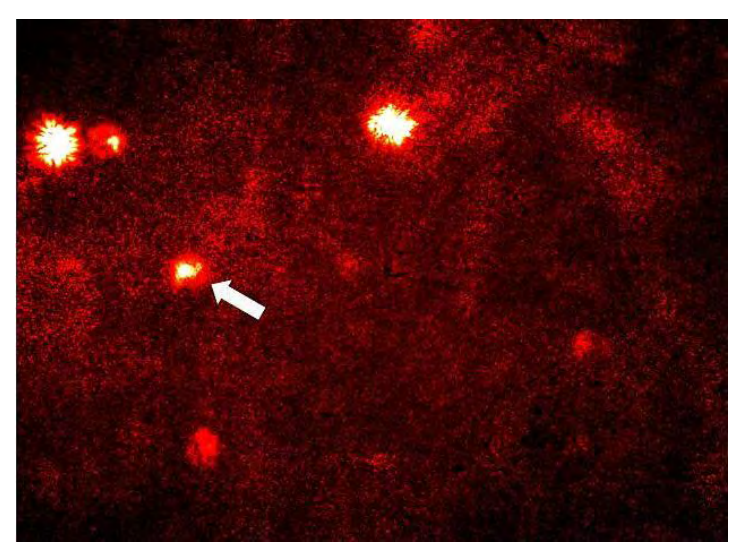

Fig. 3. The CT quinoline solution, observation in the lighting of laser beam orientated angularly to the plane of the sample (magnification of 400x)

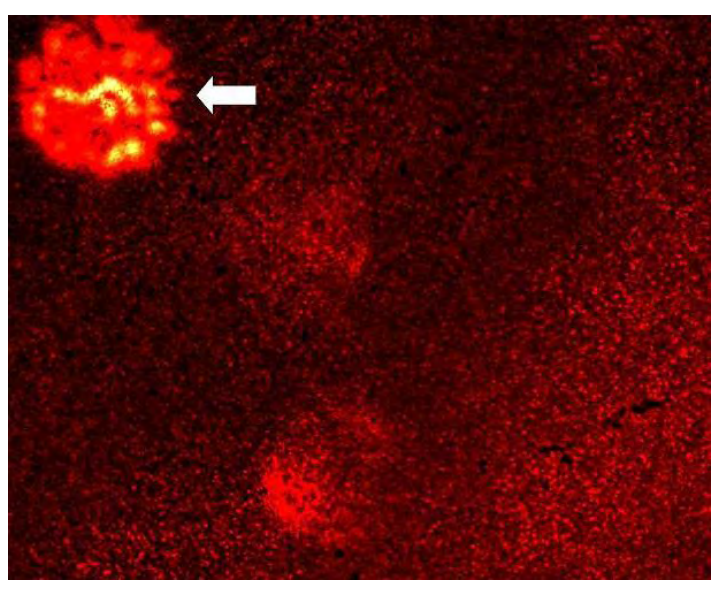

Fig. 4. The CT quinoline solution, observation in the lighting of laser beam orientated angularly to the plane of the sample (magnification of $800 \mathrm{x}$ )

It is characteristic that the shape of the aggregates is roughly global which is known to be the most energetically efficient under such conditions.

The small spots of light with which the whole field of vision is dotted are probably illuminating effects caused by the presence of the finer particles of colloidal coarseness not necessary belonging to the quinoline insolubles (the analytical methods of the group composition fractions extraction are not efficient enough to separate a true solution from a colloidal one). 
The particles of the primary $\alpha_{1}$-fraction extracted from the solution without filtration was observed by the same microscope under the phase-contrast lighting which helps to assess the surface relief of the subject visually. The characteristic images of the individual particles are shown in Fig. 5.
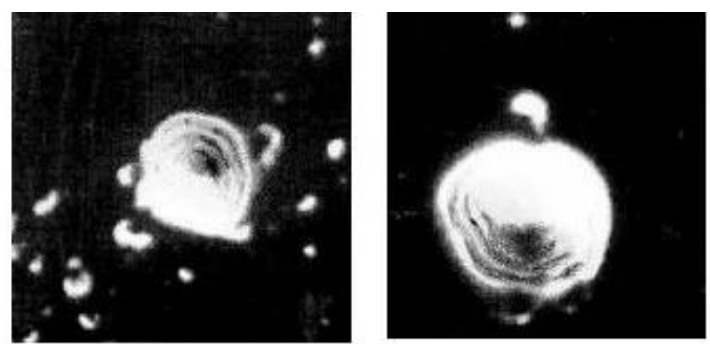

Fig. 5. Particles with the stratified surface extracted from the tar quinoline solution without the use of filtration and washing (magnification of 630x)

The stratified character of the particles surface may be explained by the following:

- $\alpha_{1}$-fraction particles serve as a kind of seeding for the vaporous hydrocarbons pyrolysis processes in the coke oven headspace (in that case the strata are the carboneous deposits);

- the strata are originated by the constituents of the quinoline soluble fractions of the $\mathrm{CT}$ group composition adsorbed on the particles surface.

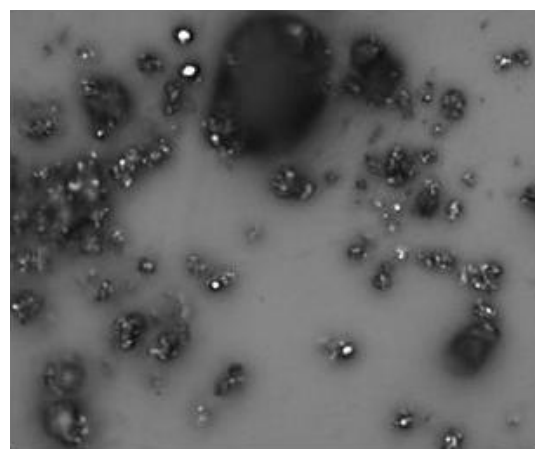

a)
The quinoline insolubles extracted by filtration were observed by the petrographic microscope (reflected light, the sample is orientated with the side under study faced up). After washing by quinoline and toluene and drying the (granular) residue from the filter was spread by a visually-even layer upon the flat surface (Fig. 6).

On the photos the trend for the particles under study to group is evident. With the increasing magnification those objects that had appeared to be the biggest of the particles proved to be either aggregates or the particles covered with the much less objects on their surface. Similar results were obtained when studying $\alpha_{1}$-fraction extracted by filtration with washing the residue in the light of laser beam orientated angularly to the sample plane (see Fig. 7). In both cases particles with a clearly stratified surface were not found.

The same sample was observed by the scanning electron microscope. The most characteristic results of the observation are shown in Fig. 8. Those include:

$I$ - coarse (more then $3 \mu \mathrm{m}$ ) globular particles with indistinctly scaly surface structure;

II - dense aggregates of the considerably finer particles (approximately $1 \mu \mathrm{m}$ or less); particles inside the aggregates adjoin each other close enough but they do not merge together - this is especially clear when increasing the microscope magnification (Fig. 8,c);

III - coarse particles of irregular shape, also with the indistinctly scaly surface.

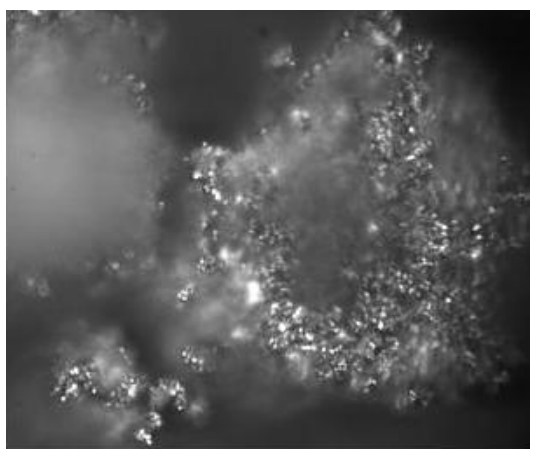

b)

Fig. 6. $\alpha_{1}$-Fraction extracted by filtration with washing of the residue, observation in reflected light: magnification of 500x (a) and 1000x (b)

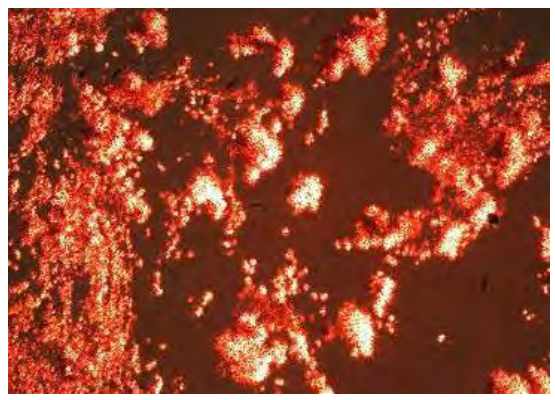

Fig. 7. $\alpha_{1}$-Fraction extracted by filtration with washing the residue, observation in the lighting of laser beam orientated angularly to the plane of the sample (magnification of 400x) 


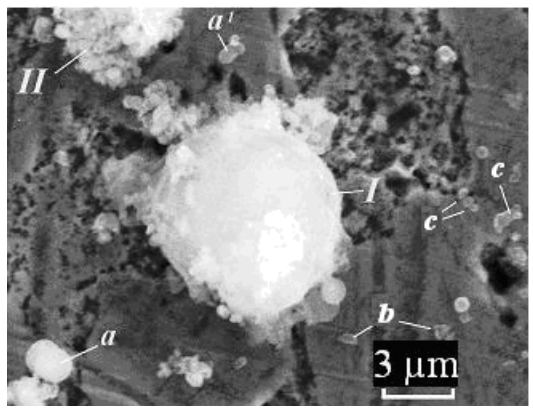

a)

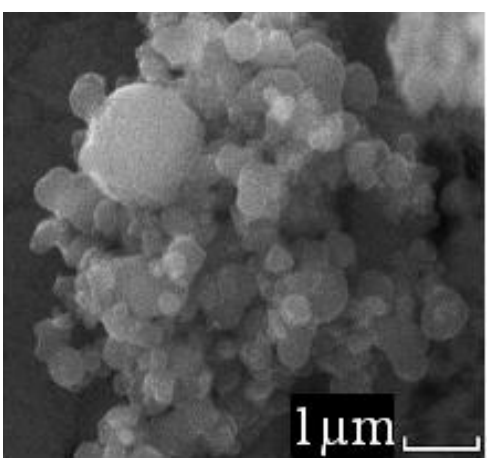

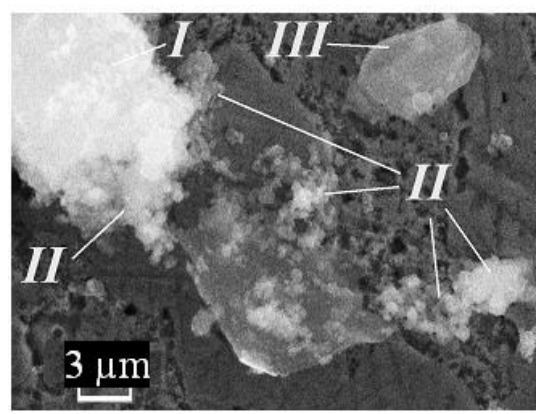

b)

c)

Fig. 8. $\alpha_{1}$-Fraction extracted by filtration with washing the residue, observation by the electron microscope: magnification of 5000x (a); 4000x (b) and 15000x (c)

Besides, the fine particles were found $(\leq 2 \mu \mathrm{m})$ with a roughly globular shape. Some of them were conglomerated into a dense adhered aggregates of 2-3 particles in which the contours of single particles were merged into each other (for example those marked in Fig. $8, a)$. Visually such aggregates are somewhat similar to the primary aggregate, Fig. 2 . The other kind of the small aggregates was notable for their un-adhered contact of the particles like in III (for example those marked in Fig. 8, $a$, $b$ ); also the hybrid aggregates were observed (for example those marked in Fig. 8, $a, a^{l}$ ) and the particles of distinctly irregular shape and size considerably less then $3 \mu \mathrm{m}$ (for example those marked in Fig. 8, $a, c$ ).

Whatever their sizes, the globular particles probably are the vapor phase pyrolisis products while the irregular shape particles - products of the $\alpha_{1}$-carryover. In some cases we succeeded to identify the scales on the particles $I$ as the globular particles of the size considerably less than $1 \mu \mathrm{m}$ aggregated on the surface. Among the particles conglomerated into aggregates III the globular particles and the two- or three-component aggregates $a$ were the most clearly visible ones.

No particles of the clearly stratified surface were found in this case as well.

The results of the study are in compliance with the conclusions represented in a number of works stated in the reference list of this essay (for example $[11,16,17]$ ); namely, the conclusion that the majority of the CT $\alpha_{1^{-}}$ fraction particles is of a size $\leq 3 \mu \mathrm{m}$. And this major fraction of texture consists mostly of the regular shape particles which are most probably products of the hydrocarbons vapor pyrolisis inside the coke oven headspace.

Proceeding from the technique of the sample preparation as well as from the results of the sequent observation we came to a conclusion that the stratified structure of the $\alpha_{1}$-fraction particles surface shown in Fig. 5 was the display of the surface adsorption of the other group composition fractions which segregated from the solution in the process of the solvent evaporation. Thus, this technique makes it possible to single out the forms which are most similar to the CT dispersed phase in its "natural" appearance.

The surface of the particles which are components of the filtered and solvent-washed residue obtained according to the quinoline insolubles mass fraction measuring technique does not show any stratified structure. This is probably a result of toluene and quinoline washing. At the same time the "scales" observed on the surface of the big globular-like particles (Fig. 8, $a, I$ ), are either densely aggregated particles of considerably less size (fractions of micron), or afterwashing leftover of quinoline solubles. In any case the particles shown in Figs. 5 and 8, $a, I$ may be considered as a proof of $\alpha_{1}$-fraction particles high surface activity in respect of the quinoline soluble part of CT (in other words in respect of the dispersion medium). This applies to the roughly globular particles in the first place. 
The considerable surface activity of the particles mentioned above in respect to each other must be mentioned as well, that is the tendency to build aggregates of the varied rates of density which are present almost in every figure. The quinoline insolubles tendency to aggregate is evident both in the solution and in the extracted residue.

The particles aggregates become almost ideally global (Figs. 3 and 4) in the solution. If the particles (globules) of the dispersed phase of emulsions tend to a global shape because of the surface tension forces than the number (and, consequently, the total energy) of collisions with the solution molecules is essential, less frequent in the direction of the closest particle. This phenomenon is known as one of the displays of Bernoulli effect [22].

The tendency of the solid particles to aggregate in a liquid medium decreases with the increase of the following characteristics:

- dispersion medium viscosity;

- mass of the particle;

- particle/medium contact surface area;

- force of friction on the phases interface.

The last three characteristics increase along with the growing of the layers adsorbed on the particles surface. At the same time the presence of such layers apparently increases the strength of inter-particle binding inside the aggregate (for account of the coherence).

The viscosity of the coal tar is higher than that of its quinoline solution. However, the high enough temperature (343-353 K) must be taken into consideration of the CT storing and pumping at the plant. Besides the highmolecular compounds concentration is considerably higher in the tar than in the solution under study. Because of that the total energy of collisions between the dispersed particles and the dispersion medium molecules is also considerably higher in the tar than in the solution. This leads to a hypothesis that the $\alpha_{1}$-particles aggregating also takes place in the CT (especially in a low-pyrolized tar with its comparatively low density and viscosity). This hypothesis is confirmed by the presence of a considerable number of the particles significantly less than $1 \mu \mathrm{m}$ that is approaching the colloidal dispersity range [23], in the residue filtered according to the analytical technique. To extract such a particles the special methods [24] are needed, more efficient than those of the quinoline insolubles mass fraction measurement of the analytical techniques. Probably, if such techniques are practiced the particles mentioned above are extracted from the tar in the form of aggregates with the similar or coarser particles. It is also probably that $373 \mathrm{~K}$ heating in quinoline and subsequent washing are not enough for the complete dissolving of those particles-adsorbed compounds the presence of which enhances the aggregates structural strength.
If the particles (maybe the ones with the adsorbed layers or maybe those in the stage of formation) are still in contact in the coke oven headspace already they bind with the building of primary aggregates which were observed in this study as the elongated particles with the characteristic smooth "waists" (Fig. 2, Fig. 8).

According to the results of observations, the particles of a globular shape have the predominant tendency to aggregate both in a solid deposition and in tar solution. Markedly irregular shaped particles $-\alpha_{1^{-}}$ carryover -tend less to the formation of aggregates.

\section{Conclusions}

1. Particles of $\alpha_{1}$-fraction of coal tar (in particular which are the products of vapor-phased pyrolysis of hydrocarbons inside the coking oven headspace) have a high propensity to form stable aggregates and to adsorption of other fractions of the group of CT on its surface.

2. Apparently, even the analytical techniques based on the use of large excesses of solvents, fail to destroy the aggregates of particles. Thus, the opinions about the negative properties of primary quinoline insolubles, formed on the basis of an analytical application of such techniques, should not be attributed to the dispersed particles themselves, but to their aggregates.

3. Surface activity of $\alpha_{1}$-fraction particles let to make the conclusion about the principal impossibility of its selective removing from the CT - especially under industrial conditions. At any attempt to remove the dispersed phase from $\mathrm{CT}$ the loss of the components responsible for the positive qualities of products is inevitable - primarily the electrode coal tar pitch (the removing $\alpha_{1}$-fraction with adsorbed components from coal tar degrades pitch properties such as yield of coke residue, the mass content of toluene insolubles, etc.).

4. On the basis of the foregoing, it is logical to assume that more promising, that the removing of $\alpha_{1^{-}}$ fractions, the method of preparing the tar for recycling would be a destruction of the aggregates of the dispersed phase. This would contribute to the conservation of valuable consumer properties of the pitch while eliminating the negative effects of the size of associated particles, as well as the overall homogeneity improvement of the CT and the electrode pitch, as the dispersed system. This technique is appropriate to implement immediately before the technological stage, leading to a significant increase of the viscosity of the dispersion medium. This will prevent or at least significantly delay the reagregation of the particles. Such a technological stage is the distillation of coal tar, during which the primary $\alpha_{1^{-}}$ fraction fully accumulates in the indistillable residue (in a pitch). 
5. In any case, the results obtained in the course of these studies showed that the research previously undertaken for unbundling of the CT dispersed phase [25] should be still actual and should be continued. Basing on data, obtained earlier, and on the results, described in this article, we can suggest that the most promising areas of searching such methods of effecting the coal tar are the following:

- hydraulic shock;

- cavitation.

\section{Acknowledgements}

The author expresses his thanks to the staff of UKHIN Ph.D. V. M. Shmalko, V. V. Karchakova and G. G. Achkasova for their invaluable assistance in these studies.

\section{References}

[1] Gogoleva T. and Shustikov V.: Himia i Technologia Pererabotki Kamennougolnoi Smoly. Metallurgia, Moskwa 1992.

[2] Pitiulin I.: Nauchno-Tehnologicheskie Osnovy Sozdania Kamennougolnyh Uglerodsoderzshastchih Materislov dlia Krupnogabaritnyh Elektrodov. IPC «Kontrast», Kharkov 2004.

[3] Mochalov V., Gajsarov M., Popov V. et al.: Koks i Khimiya, $1985,4,33$

[4] Sidorov O. and Kondratiev V.: Koks i Khimiya, 1988, 3, 25.

[5] Mariich L. and Zshabotinskaja S.: Koks i Khimiya, 1986, 10, 33.

[6] Siuniaev Z., Siuniaev R. and Sofieva R.: Neftianye Dispersnye Systemy. Khimiya, Moskwa 1990.

[7] Mochalov V.: [in:] Sbornik Nauchn. Trudov NIIGrafit, GOSNIIEP. NIIGrafit, Moskwa 1986, 5.

[8] Kovalov Y.: Nauchnye Osnovy i Technologia Pererabotki Vysokokipyastchih Frakcyi Kamennougolnoi Smoly s Polucheniem Polycyclicheskih Uglevodorodov. IPC «Kontrast», Kharkov 2001.

[9] Cheshko F.: PhD thesis, Kharkiv, Ukraine 1997.

[10] Kovalov Y. (Ed.): Spravochnik Koksohimika. V. 3. ID INZSHEK, Kharkov 2009.

[11] Romovacek G.: Carbon, 1986, 24, 417.

[12] Babenko E., Slepova V. and Balykin V.: [in:] Sbornik Nauchn. Trudov NIIGrafit, GOSNIIEP. NIIGrafit, Moskwa 1986, 81.
[13] Markov V., Petropolskaja V. and Batyeva T.: Koks i Khimiya, $1984,8,31$.

[14] Karpin G., Tesalovskaja T., Reshetko A. et al.: Koks i Khimiya, 1987, 5, 32.

[15] Tesalovskaja T., Karpin G., Andreikov E. et al.: Koks i Khimiya, 1987, 10, 32.

[16] Cheshko F., Pitiulin I., Pyrin A. et al.: Uglekhim. Zh., 1995, 12,53 .

[17] Pitiulin I., Virozub A., Pyrin A. et al.: Uglekhim. Zh., 1995, 3-4, 40.

[18] Gluzman L. and Edelman I.: Laboratornyi Control Koksohimicheskogo Proizvodstva. Metallurgia, Moskwa 1968.

[19] Skripchenko N., Cheshko F., Bannikov L. and Rudkevich M.: Uglekhim. Zh., 2010, 5-6, 55.

[20] Kouzov P.: Osnovy Analiza Dispersnogo Sostava Promyshlennyh Pylei i Izmelchennyh Materialov. Khimiya, Leningrad 1987.

[21] http://bse.sci-lib.com/article114018.html

[22] Mihajlovskij V.: Kolloid. Zh., 1993, 55, 124.

[23] Fridrihsberg D.: Kurs Kolloidnoi Khimii. Khimiya, Leningrad 1984.

[24] Malinovskaja T.: Razdelenie Suspenzij v Promyshlennosti Organicheskogo Sinteza. Khimiya, Moskwa 1971.

[25] Cheshko F., Vainblat I. and Selianko I.: [in:] Tемatich. Sbornik Nauchn. Trudov UKHIN, VUKHIN. Metallurgia, Moskwa 1988, 15.

\section{МІКРОСКОПІЧНІ ДОСЛІДЖЕННЯ ЧАСТИНОК ВУГЛЕЦЕВИСТОЇ ДИСПЕРСНОЇ ФАЗИ КАМ'ЯНОВУГІЛЬНОЇ СМОЛИ}

Анотація. Наведено результати мікроскопічних досліджень дисперсної вуглецевистої фази кам'яновугільної смоли, виконані з використанням мікроскопів різних принципів дії. Показано високу схильність дисперсних частинок до утворення стійких агрегатів та до адсорбування на своїй поверхні інших компонентів смоли. Зроблено висновок щчодо принцииповоі неможливості вибіркового видалення дисперсної фази з кам'яновугільної смоли. Висловлено обтрунтоване припущення про технологічну доиільність руйнування агрегатів дисперсної фази смоли з точки зору поліпшення якості продуктів на ї̈ основі.

Ключові слова: кам'яновугільна смола, дисперсна фаза, дисперсійне середовище, речовини, нерозчинні в хіноліні, частинки, мікроскопія, агрегаиія, поверхня. 